\title{
DIVERSIONES PÚBLICAS Y ESTADO EN NICARAGUA 1877-1936
}

\author{
Chester Urbina Gaitán
}

Recibido: 20/10/2014 Aceptado: 31/03/2015

\begin{abstract}
Resumen
El control del Estado nicaragüense de las diversiones públicas y del tiempo libre durante el periodo 1877-1908 giró alrededor del respeto al tiempo laboral y la no participación en lugares de juego de algunos sectores sociales, entre ellos los menores de edad. Para el periodo de 1909 a 1936 ademásde mantenerse estas disposiciones se tiene que las diversiones públicas fueron usadas para mantener la ocupación estadounidense, siendo el beisbol la actividad más promocionada.
\end{abstract}

Palabras clave: Nicaragua; Estado; ocupación estadounidense; diversiones públicas; tiempo libre.

\begin{abstract}
The Nicaraguan state control of public entertainment and leisure time during the years of 1877-1908 revolved around respect for the working time and the nonparticipation in gambling venues of some social sectors including minors. For the period 1909-1935 these provisions remain in effect and also public diversions were used to keep the U.S. occupation, being baseball the most promoted activity.
\end{abstract}

Key words: Nicaragua; state, U.S. occupation; public entertainment; free time.

El estudio de la evolución del Estado evidencia que al entrar al último cuarto del siglo XIX se hizo un esfuerzo coherente de la clase gobernante por consolidar la hegemonía estatal. El general José Santos Zelaya se planteó crear la nación desde el Estado. La expansión cafetalera necesitó que el Estado asumiese las tareas de crear las condiciones económicas, políticas y sociales para su desarrollo. De este modo, el gobierno de Zelaya (1896-1909) intensificó la modernización del Estado, al favorecer el desarrollo del cultivo del café y su inserción en el mercado mundial.

Asimismo, tomó una serie de medidas surgidas del marco jurídico institucional de la Revolución Liberal con la Constitución de 1894 y de la promulgación de códigos y leyes que ordenaron el funcionamiento estatal y social, establecieron la separación entre la Iglesia y el Estado. Se introdujeron, además, el derecho de propiedad y seguridad 
individual, la educación laica y gratuita, y se crearon instituciones gubernamentales que facilitaron las gestiones para la producción y el comercio, y la conformación de un ejército moderno. Su logro más importante fue la incorporación de La Mosquitia al territorio nacional.

A raíz de la ocupación estadounidense, a partir de 1909, la formación del Estado-nación entró en una nueva fase. El Estado se mantenía porque estaba protegido por el gobierno de los Estados Unidos, cuyo interés era crear un Estado fuerte para garantizar la estabilidad de Centroamérica. Para esto fue necesaria la creación de instituciones que encarnaran el Estado. Así, en 1911, se creó la Recaudación General de Aduanas, en 1912 se fundó el Banco Nacional, en 1917 se estableció la Alta Comisión, encargada del manejo del Presupuesto Nacional, en 1923 se elaboró la ley Dodds, ley electoral que estuvo vigente, con algunas reformas, hasta 1979 y, finalmente, en 1928 se creó la Guardia Nacional. A la vez que el Estado intervenía, perdía sus principales atribuciones y se formaban las principales instituciones del Estado moderno nicaragüense.

Sobre estas instituciones se estableció la dictadura de los Somoza (1936-1979). Según Acuña (2012), durante la ocupación, Nicaragua no era un Estado nacional, sino una dependencia con instituciones públicas administrada por un Estado imperial, instituciones cuyos objetivos no eran los de la nación o más precisamente de sus élites dominantes, sino los de la potencia imperial.

Con respecto al uso ideológico del tiempo libre en Nicaragua -específicamente en el teatro- a finales del siglo XIX, Fumero (1996) refiere que el espacio de sociabilidad ofrecido por el teatro sobrepasó los límites de la ciudad, e involucró a los sectores populares -especialmente urbanos- y a sujetos de otras provincias. De esta forma, el teatro respondió a las nuevas exigencias de los procesos de urbanización y de "civilización", los cuales configuraron, a su vez, nuevas relaciones sociales. Sin embargo, en Nicaragua no se consolidaron debido a una cierta discontinuidad, dados los problemas que enfrentaron los locales construidos en León y Granada a finales del siglo XIX (Molina y Fumero, 1997). Por su parte, Richard McGehee ha explorado el vínculo del deporte -principalmente el beisbol- en las celebraciones tradicionales nicaragüenses (McGehee, 1996).

En cuanto a la calidad en el consumo de las diversiones públicas, Herrera (1976) señala que en ellas no se experimentó la diferenciación de clase, cuando Mariano Salazar presentó en su casa a los funambuleros de la Compañía de Pedro Serrate, él pudo disfrutar de los réditos políticos que le proporcionó la presencia de la muchedumbre leonesa, y junto con ella disfrutó del espectáculo en su casa. Sin embargo, la ausencia de un capital cultural común, con la carencia de bagaje intelectual les impidió disfrutar la calidad del evento y el artista solo frustraciones percibió. El capital cultural predominante era el de la iglesia (Herrera, 1996).

El país centroamericano donde más se ha abordado el tema de las diversiones públicas y su control estatal para los años de análisis es Costa Rica, donde se encuentran 
los siguientes trabajos: Molina y Palmer (1992 y 1994), Molina (1995), Fumero (1996), Acuña et al. (1996), Enríquez (1998) y Urbina (1999, 2000, 2001 y 2002). En general, estas obras afirman que el Estado usó la sociabilidad para transmitir patrones culturales e identitarios - principalmente de tipo nacionalista- con el fin de mantener el respeto a la jerarquía de clase. Sin embargo, su control social se concentró alrededor del Valle Central, región que articulaba en torno a sí la idea de nación.

Para el caso guatemalteco se pueden mencionar los trabajos de Dary (1993) y Urbina (2006 y 2007); para El Salvador se encuentran las siguientes obras de Urbina (2003, 2007 y 2008). En estos últimos países, a finales del siglo XIX, surge y se expande una idea de nación acantonada principalmente en el espacio geográfico del centro y occidente de Guatemala y de El Salvador, zonas que -al igual que el Valle Central costarricense- concentraban la mayoría de la población y las mejores instalaciones educativas. Además, en estas regiones residía el grueso del capital proveniente de la actividad cafetalera y las más modernas vías y medios de comunicación que permitieron elevar el nivel de vida cultural de los sectores campesinos y trabajadores citadinos. Todo esto hizo que, paulatinamente los patrones de relación entre los sectores subordinados fueran trastocándose e identificándose con otros más liberales, seculares y cosmopolitas (Urbina, 2006).

Fundamentado en el contexto anterior se justifica el propósito de este artículo al analizar el control ejercido por el Estado nicaragüense dentro del período 1877-1936 en torno al uso ideológico del tiempo libre, de las diversiones públicas como el teatro, el cine y el beisbol, y su utilización como un mecanismo informal de morigeración de las costumbres de los sectores populares. Cabe destacar que estas diversiones públicas forman parte de la cultura urbana, cosmopolita y laica de Nicaragua durante los años de análisis, y fueron los ejes sobre los cuales giró la cultura de masas. El periodo de estudio se centra en los años en que el Estado nicaragüense comenzó a crear cierto sistema de control social en el país que va desde 1877 hasta 1936 con la llegada al poder de la dictadura de los Somoza.

\section{Diversiones públicas, morigeración de las costumbres y Estado en Nicaragua (1877-1936)}

El 30 de agosto de 1878 el periódico La Tertulia -fundado en 1875 por el historiador Jerónimo Pérez- daba a conocer su preocupación con respecto a las diversiones tradicionales que se darían en las fiestas patronales de la ciudad de Masaya:

Con motivo de la próxima fiesta, se están proyectando algunas alegríaspara atraer concurrentes de todos los pueblos, cosa que nos llena deplacer; pero no podemos menos que lanzar un grito de horror cuando oimoshablar de toros i juegos prohibidos, porque si los primeros son una diversiónbárbara, los segundos son inmorales, hasta el extremo (La Tertulia, 1878: 286). 
Este llamado de atención forma parte del interés de la clase dominante nicaragüense -desde finales del siglo XIX- por articular cierto sistema de vigilancia, supervisión y control de las diversiones de los sectores populares. Sin embargo, la prensa del período en estudio es parca en demostrar la forma en que los nicaragüenses aceptaron, rechazaron o mediatizaron estas disposiciones estatales. En 1877, se dispuso derogar un decreto emitido en 1866 donde se prohibía la práctica del dominó; lo cual se fundamentó en el hecho de que el buen éxito para el jugador dependía de su inteligencia, por lo que no era perjudicial para la moral de los pueblos del país (La Gaceta, 1877: 341). En 1879 se dispone que toda fiesta pública solo podía durar tres días (La Gaceta, 1879: 411). Para 1890 se emitió el Reglamento de la Policía Urbana de Managua, donde se acuerda que los policías debían controlar que las taquillas, cantinas, billares y demás establecimientos de juegos permitidos, no abrieran antes ni cerraran después de las horas señaladas. Asimismo, debían evitar que los menores de edad, clérigos y maestros de primeras letras concurrieran a estos lugares. Los maestros $\mathrm{u}$ oficiales de cualquier arte $\mathrm{u}$ oficio y los jornaleros que en día de trabajo y a las horas no permitidas se encontraran en los billares, tabernas o casas de cominería, serían multados con la suma de cinco pesos, la primera vez, de diez en la segunda y de quince en los demás casos de reincidencia (La Gaceta, 1890: 241). Lo mismo se dispone en el Reglamento de la Policía Republicana o Guardia Civil Urbana de 1895 (La Gaceta, 1895: 2). Para 1918 se prohibió el juego de lotería china (La Gaceta, 1918: 841).

\section{Casas de juegos}

En 1904, se emitió el Reglamento de las Casas de Juego, en el cual el Poder Ejecutivo, para dar autorización a tales establecimientos tomaba como requisito fundamental, si en las poblaciones existía la vigilancia policial. En atención a la cuota o contribución pecuniaria a que estuvieran sujetas y a su situación en la localidad, las casas serían de dos categorías: de primera y de segunda clase. En ese momento solo se podrían establecer las siguientes casas: dos de primera y dos de segunda en Managua; una de primera y dos de segunda en León y Granada y una de primera en Bluefields. Una de segunda en las demás cabeceras departamentales y de Distrito, en los puertos de Corinto, San Juan del Sur, San Juan del Norte, Rama y Cabo Gracias a Dios y en las poblaciones en donde existieran los medios eficaces para una vigilancia activa y verdadera, a juicio del Ministerio de Policía.

Las casas de juego solo podían estar abiertas losdomingos y días de fiesta todo el día hasta las doce de la noche; los días de trabajo desde las siete de la tarde hasta las doce de la noche. Durante ese tiempo mantendrían siempre abierta la puerta exterior. Estas casas no admitían bajo ningún concepto a los estudiantes y a los menores de 21 años de edad, si eso sucedía estos locales pagarían la multa de cien 
pesos las de primera clase, y cincuenta pesos las de segunda. En caso de reincidencia se suspendería temporalmente el establecimiento, según la gravedad de la falta.

En las poblaciones donde no hubiera casas establecidas, el Ministerio de Policía podría conceder licencias para juegos de azar durante el tiempo que duraran las respectivas fiestas patronales, sujetándose a una reglamentación especial y dedicando siempre el producto a los mismos objetos que fueran indicados. Toda casa de juegos debe elaborar un reglamento interior y una tarifa de lo que debía cobrar a sus clientes, que sujetaría a la aprobación del Ejecutivo, y colocaría tres ejemplares impresos en el lugar más visible del establecimiento para que el público pudiera enterarse de ellos.

Toda persona que se encontrara jugando al azar en casas no autorizadas se verá expuesta a una multa de diez pesos en la primera vez, duplicándose progresivamente en las demás infracciones, mientras que el dueño o promotor del juego deberá cancelar una multa de cien pesos. No se podría establecer una casa de juegos cerca de los centros educativos o de los cuarteles. Todo dueño o encargado de una casa de juegos estaba obligado a permitir la entrada y registro del establecimiento a los agentes de policía, o agentes de la autoridad; en caso contrario se vería expuesto a una multa de cincuenta a cien pesos.

La concesión para establecer una casa de juegos debía de aplicarse para los de envite o azar, con exclusión de la ruleta, pues para este juego se necesitaba una licencia especial, y podría establecerse solo o en casas de primera clase. Además, estaba prohibido a los militares uniformados entrar en las casas de juegos, a menos que fuera por motivos de trabajo (La Gaceta, 1904).

\section{Teatro}

En 1913 se aprueba el Reglamento de Teatros y Espectáculos Públicos, el cual señalaba que la inspección de todos los espectáculos públicos le correspondía a la Secretaría de la Gobernación. Esta dependencia debía nombrar a dos empleados, que se denominarán $1^{\circ}$ y $2^{\circ}$ Juez de Espectáculos Públicos, para la inmediata vigilancia de los mismos. En los demás departamentos, la mencionada dependencia pública delegaría sus facultades a los jefes políticos.

Además, toda empresa debía solicitar a la Secretaría de la Gobernación el permiso para presentar los espectáculos; especificando en la solicitud el género de estos. Toda empresa teatral estaba obligada a acatar respetuosamente las indicaciones de los Jueces de Espectáculos. También, la empresa estaba obligada a brindar una actuación a beneficio de la Junta de Beneficencia del lugar y, a la vez, la empresa debía dar estricto cumplimiento al programa anunciado, salvo en caso fortuito o de fuerza mayor. La empresa no podría vender localidades, en un número mayor que el que haya sido autorizada.

Todo espectáculo debía iniciar a la hora señalada en el programa. Esta hora en ningún caso podrá sobrepasar las ocho y media de la noche. La infracción de este 
artículosería penada con una multa de diez a veinticinco córdobas. El local deberá abrir sus puertas por lo menos media hora antes de que inicie el espectáculo público. Por su parte, durante las presentaciones, las puertas del local debían permanecer abiertas, en caso de cualquier emergencia, y deberánabrirse hacia afuera. Los programas de cualquier espectáculodebían ser sometidos a la aprobación de los Jueces de Espectáculos antes de su publicación. Las personas que formaran parte de un espectáculo público, de cualquier género, debían guardar perfecta decencia, compostura en sus trajes, gestos y palabras; además, se les prohibía en absoluto interpelar y dirigirse nominativamente a alguno o algunos de los espectadores, así como hacer alusiones personales o políticas de actualidad local, sin licencia del censor.

Al mismo tiempo, los espectadores estaban obligados a aguardar orden y compostura. En las representaciones que fuera preciso guardar silencio, no era lícito hablar ni hacer ruido de ninguna clase, y mucho menos hacer manifestaciones exageradas que alteraran el orden y fueran contrarias al decoro. Si alguna de estas situaciones se presentara, los Jueces de Teatros procederían a la expulsión de quienes alteraran el orden.

Además era prohibido fumar y escupir dentro de las localidades para los espectáculos públicos. Se podía fumar solo en los lugares destinados para ese fin; tampoco era permitido interrumpir el libre tránsito del público, ya fuera formando grupos en los pasillos, escaleras o puertas. Las personas que causaran daños al edificio, muebles o enseres, donde se realizaran los espectáculos, pagarían a la empresa teatral los daños causados, sin perjuicio de las penas que las autoridades aplicaran. Estaba prohibida la entrada a niños menores de cuatro años, y lasmujeres consideradas de mala reputación no podían accesar a los palcos; en ese caso la Empresa devolvería el valor total de la entrada. Los empleados de todo espectáculo estaban obligados a avisar a tales mujeres la prohibición anterior. Los Jueces de Espectáculos Públicos tendrían bajo sus órdenes a los agentes de policía que creyeran convenientes para guardar el orden y hacer cumplir todas las disposiciones. Al tiempo que la empresa estaba obligada a dar entrada a estos policías (La Gaceta, 1913: 2-3.; La Gaceta, 1919: 1857-1858 y La Gaceta, 1921: 1158).

Este Reglamento se mantuvo en vigencia hasta 1927, cuando se emitió el Reglamento de Teatros, Espectáculos Públicos y Cinematógrafos. Anivel general, este nuevo reglamento mantenía los mismos acuerdos del anterior en cuanto al teatro.

\section{Cine}

Con respecto al cine, se disponía que las empresas cinematográficas que estuvieran arraigadas de forma permanente en la localidad dieran a beneficio de la Junta, por lo menos, una función anual. A excepción de las empresas que debieran pagar impuestos especiales a las Juntas. 
Las funciones cinematográficas se dividían en dos clases: funcionespara niños y funciones para adultos. Los niños mayores de seis años y menores de trecesolo podrían asistir a funcionescalificadas por la censura como propias para niños, además deberían asistirían acompañados de sus padres o de sus tutores; en ningún caso se les admitiría con solo la sirviente o el sirviente. Las funciones para niños debían someterse a las siguientes condiciones:

1. La función no se prolongaría más allá de las nueve de la noche.

2. La película debía haber sido aprobada por los censores como propia para niños.

Los Censores solo podrían calificar como propias para niños las siguientes películas: películas de vulgarización científica, películas cómicas, películas llamadas de actualidad, películas panorámicas, películas de comedias adecuadas ypelículas que contuvieran un entretenimiento sencillo e inofensivo.

Asimismo quedaban excluidas aquellas cuyo argumento o la manera como se representaran fueran, en su totalidad o en parte, de tal naturaleza que pudieran ejercer una influencia perniciosa sobre el carácter de los niños, o sobre su desarrollo mental o sexual, o que pudieran sobre excitar su imaginación. También se prohibían las películas que fueran perjudiciales para la educación del niño, tales como las policíacas, las intensamente dramáticas, las que contribuyeran a fomentar sentimientos hostiles para con otros países y, en general, las que, según opinión de los censores, produjeran un efecto pernicioso sobre el ánimo de los jóvenes, o sobre sus ideas del bien y del mal.

Asimismo, estaba prohibida la entrada a los menores de trece años a las funcionespara adultos. Los censores estaban obligados a prohibir, aún para adultos, las escenas o las películas manifiestamente inmorales, obscenas ocontrarias a las buenas costumbres; las relativas a la trata de blancas, las de seducción y disolución, las escenas horripilantes y macabras; por ejemplo ahorcamientos, linchamientos, electrocución, locura, delirio, embriaguez manifiesta; así como las imágenes de personas consideradas como de mala fama, de toxicómanos, de falsificadores de monedas, de personas que cometan actos de crueldad con sus semejantes o con los animales. También, las películas cuya exhibición pudiera amenazar el orden público, o herir los sentimientos religiosos, o producir un efecto embrutecedor o desmoralizador, o disminuir el prestigio del país o de los otros que forman Centroamérica, o turbar las relaciones de Nicaragua con los países extranjeros. Se prohibía, finalmente, el uso de expresiones groseras y de títulos inconvenientes (La Gaceta, 1927: 1401-1403, 1409-1412, 1417-1419). Estas prohibiciones en el cine al igual que las emitidas en el Reglamento de Teatros y Espectáculos Públicos de 1913 fueron emitidas dentro del contexto de ocupación estadounidense y buscaban evitar posibles alzamientos políticos que sacaran a Nicaragua de esta situación. 


\section{Beisbol}

Por último, con respecto al control sobre el beisbol, se conoce que en 1915 se produjeron algunos desórdenes en algunos partidos de este deporte. Esto llevó a que se emitiera una disposición donde se acordó que en los partidos de cualquier deporte donde existieran apuestas debían verificarse en el lugar donde se le señalara a los jefes políticos departamentales. La contravención a esto sería penada con una multa de ocho córdobas, a favor de la Junta de Beneficencia donde la hubiere, o de los fondos municipales donde no existieran tales juntas. Los partidos en mención no podrían realizarse en días de trabajo, antes de las cinco de la tarde, salvo que el Jefe Político hubiera concedido permiso. La policía vigilaría estos encuentros y dictaría las medidas necesarias para evitar desgracias (La Gaceta, 1915). Este control se reforzó aún más en 1932 cuando se aprueban las Reglas Oficiales para la práctica de esta disciplina deportiva. En este reglamento se establecen todas las normativas a observar para la correcta ejecución de un partido de beisbol. Fundamentado en todo lo anterior es que se afirma que el beisbol -el deporte de mayor preferencia de los ocupantes estadounidenses-fue reglamentado y controlado para que se pudiera ejecutar sin ningún tipo de problemas en su expectación y práctica, lo que pretendía su propagación por todo el país.

Estas reglas fueron elaboradas por la Comisión Nacional de Deportes, la cual se creó en 1931, y tenía la suprema vigilancia, organización, control y autoridad sobre todos los deportistas y deportes que se practicaran en el país; y actuaría como Supremo Tribunal para dirimir discordia o diferencias en fallos o quejas que se le sometieran a su conocimiento y actuaría de oficio cuando se tratara de la infracción de leyes, disposiciones o reglamentos de los juegos por parte de los jueces, clubes o deportistas y en todos los casos en que ella creyera necesaria su intervención, siendo inapelables ulteriormente sus resoluciones o fallos. La Comisión estableció que existirían dos clases de Ligas Deportivas: las Nacionales y las Departamentales que serían anuales y únicamente para beisbol, fútbol y baloncesto (La Gaceta, 1932: 1313-1315, 1322, 1324, 1331-1332, 1340-1341, 1348-1349, 1356, 1363-1364, 1371-1372, 1379-1380, 1388-1389, 1394, $1403,1413,1419-1420,1429,1434,1443-1444$ y 1451-1453). Estos deportes son de práctica colectiva y han sido utilizados para generar réditos políticos y hacer buena imagen.

Debe aclararse que el control estatal hacia las diversiones públicas antes analizadas fue muy pobre debido a la guerra con Honduras de 1907, la caída de José Santos Zelaya en 1909, los alzamientos políticos y la crisis política que hubo en el país previa a la ocupación norteamericana de 1912. Durante el período de la ocupación estadounidense (1912-1933), el Estado nicaragüense fue manejado por Estados Unidos y la educación formal e informal recibió un apoyo mínimo (Rodríguez, 2005). Sin embargo, su influencia se concentró en las principales ciudades y puertos de la región del Pacífico como: el puerto de Corinto, y las ciudades de León, Managua, Masaya y Granada principalmente. 


\section{Conclusiones}

Del análisis de la legislación emitida sobre el control del tiempo libre y de las diversiones públicas de 1877 a 1908 se tiene que este giraba alrededor del respeto al tiempo laboral y la no participación en lugares de juego -como taquillas, cantinas, billares y demás establecimientos de juegos permitidos- de menores de edad, clérigos, maestros de primeras letras y militares. Sin embargo, el control del Estado nicaragüense sobre las diversiones publicas fue muy exiguo debido a a la guerra con Honduras de 1907, la caída de José Santos Zelaya en 1909, los alzamientos políticos y la crisis política que hubo en el país previa a la ocupación norteamericana de 1912. Durante el período de la ocupación estadounidense (1912-1933) el Estado nicaragüense fue manejado por Estados Unidos y la educación formal e informal recibió un apoyo mínimo.

A partir de 1909, se pretendió que el espectáculo ofrecido ayudara a la beneficencia pública, amén de impedir manifestaciones que alteran el orden y fueran contrarias al decoro. En el caso del cine se impidió que este espectáculo contribuyera a fomentar sentimientos hostiles para con otros países; que produjeran un efecto pernicioso sobre el ánimo de los jóvenes, o sobre sus ideas del bien y del mal. En el cine se hizo hincapié en no presentar películas que disminuyeran el prestigio del país o de los otros que formaran Centroamérica, o turbar las relaciones de Nicaragua con los países extranjeros. Esto se hizo para evitar posibles alzamientos políticos que sacaran a Nicaragua de la intervención estadounidense. Acerca del beisbol -el deporte de mayor preferencia de los ocupantes estadounidenses- este fue reglamentado y controlado para que se pudiera ejecutar sin ningún tipo de problemas en su expectación y práctica, lo que pretendía su propagación por todo el país. Por último, se tiene que la actividad deportiva se centralizó en Nicaragua en 1931 con la fundación de la Comisión Nacional de Deportes. Todo esto permite afirmar que las diversiones públicas durante el periodo de ocupación estadounidense fueron usadas por el Estado para mantener esta situación, siendo el beisbol la actividad más promocionada.

\section{Bibliografía}

Asamblea Nacional Legislativa. "Reglamento de la Policía Republicana o Guardia Civil Urbana". La Gaceta 149 del jueves 2 de mayo de 1895, 2.

Cartera de Gobernación. "Reglamento de Teatros y Espectáculos Públicos". La Gaceta 98 del viernes 2 de mayo de 1913, 2-3.

Cartera de Policía. "Acuerdo del 5 de agosto de 1915". La Gaceta 178 del 7 de agosto de 1915, 1. Cartera de Gobernación y Policía. Decreto No. 20. La Gaceta 233 del sábado 11 de octubre de $1919,1857-1858$.

. Decreto No. 64. La Gaceta 146 del miércoles 29 de Junio de 1921, 1158.

Reglamento de Teatros, Espectáculos Públicos y Cinematógrafos. La Gaceta 176 del martes 9 de agosto de 1927, 1401-1403. 
Reglamento de Teatros, Espectáculos Públicos y Cinematógrafos. La Gaceta 177 del jueves 11 de agosto de 1927, 1409-1412.

Reglamento de Teatros, Espectáculos Públicos y Cinematógrafos. La Gaceta 178 del viernes 12 de agosto de 1927, 1417-1419.

Dary Fuentes, Claudia. "Diversiones Populares en la ciudad de Guatemala: Circos y Funambulistas (1847-1898)". La Tradición Popular, 92(1993): 1-10.

El Estado de Nicaragua. En línea. <http://www.resdal.org/Archivo/nica-libro-blanco-capitulo1.pdf $>$.

Enríquez Solano, Francisco José. Diversión pública y sociabilidad en las comunidades cafetaleras de San José: El caso de Moravia (1890-1930). Tesis de Maestría en Historia, Universidad de Costa Rica, 1998.

Fumero Vargas, Patricia. Teatro público y Estado en San José 1880-1914. Una aproximación desde la historia social. San José: EUCR, 1996.

Gobernación y Anexos. "Reglas oficiales para Base Ball, elaboradas por la Comisión Nacional de Deportes". La Gaceta 141 del martes 5 de julio de 1932, 1313-1315.

"Reglas oficiales para Base Ball, elaboradas por la Comisión Nacional de Deportes". La Gaceta 142 del miércoles 6 de julio de 1932, 1322.1324.

"Reglas oficiales para Base Ball, elaboradas por la Comisión Nacional de Deportes". La Gaceta 143 del jueves 7 de julio de 1932, 1331-1332.

"Reglas oficiales para Base Ball, elaboradas por la Comisión Nacional de Deportes". La Gaceta 144 del viernes 8 de julio de 1932, 1340-1341.

"Reglas oficiales para Base Ball, elaboradas por la Comisión Nacional de Deportes". La Gaceta 145 del sábado 9 de julio de 1932, 1348-1349.

. "Reglas oficiales para Base Ball, elaboradas por la Comisión Nacional de Deportes". La Gaceta 146 del lunes 11 de julio de 1932, 1356.

"Reglas oficiales para Base Ball, elaboradas por la Comisión Nacional de Deportes". La Gaceta 147 del martes 12 de julio de 1932, 1363-1364.

. "Reglas oficiales para Base Ball, elaboradas por la Comisión Nacional de Deportes". La Gaceta 148 del martes 13 de julio de 1932, 1371-1372.

"Reglas oficiales para Base Ball, elaboradas por la Comisión Nacional de Deportes".

La Gaceta 149 del viernes 15 de julio de 1932, 1379-1380.

. "Reglas oficiales para Base Ball, elaboradas por la Comisión Nacional de Deportes". La Gaceta 150 del sábado 16 de julio de 1932, 1388-1389.

"Reglas oficiales para Base Ball, elaboradas por la Comisión Nacional de Deportes". La Gaceta 151 del lunes 18 de julio de 1932, 1394.

. "Reglas oficiales para Base Ball, elaboradas por la Comisión Nacional de Deportes". La Gaceta 152 del martes 19 de julio de 1932, 1403.

"Reglas oficiales para Base Ball, elaboradas por la Comisión Nacional de Deportes". La Gaceta 153 del miércoles 20 de julio de 1932, 1413.

"Reglas oficiales para Base Ball, elaboradas por la Comisión Nacional de Deportes". La Gaceta 154 del jueves 21 de julio de 1932, 1419-1420.

"Reglas oficiales para Base Ball, elaboradas por la Comisión Nacional de Deportes". La Gaceta 155 del viernes 22 de julio de 1932, 1429.

. "Reglas oficiales para Base Ball, elaboradas por la Comisión Nacional de Deportes". La Gaceta 156 del sábado 23 de julio de 1932, 1434. 
“Reglas oficiales para Base Ball, elaboradas por la Comisión Nacional de Deportes". La Gaceta 157 del lunes 25 de julio de 1932, 1443-1444.

. "Reglas oficiales para Base Ball, elaboradas por la Comisión Nacional de Deportes". La Gaceta 158 del martes 26 de julio de 1932, 1451-1453.

La formación del Estado en Nicaragua y Costa Rica en perspectiva comparada: siglos XIX-XX. En línea. <https://www.american.edu/clals/upload/264n-del-Estado-en-Nicaraguay-Costa-Rica-en-perspectiva-comparada.pdf $>$

La Tertulia, agosto 30 de 1878, Año IV, N. ${ }^{\circ}$ 36, 286.

Herrera C., Miguel Ángel. "Sombreros, frac, tiste y poder". Ponencia del III Congreso Centroamericano de Historia. San José, Costa Rica. 15 al 18 de julio de 1996.

Hacer historia en El Salvador. En línea. <http://www.hacerhistoriasv.org/>.

McGehee, Richard V. "El papel del deporte en la cultura popular nicaragüense, 1889-1923". Ponencia presentada en el III Congreso Centroamericano de Historia. San José, Costa Rica. 1996.

Ministerio de la Gobernación. "Reglamento de la Policía Urbana de Managua”. La Gaceta 55 del miércoles 12 de marzo de 1890, 241.

Ministerio de Gobernación y sus anexos. "Se reglamenta las Casas de Juegos". La Gaceta 2380 del 29 de noviembre de 1904, 1.

Ministerio de Gobernación, Policía y Negocios Eclesiásticos. "Acuerdo, derogando el art. $1^{\circ}$ del decreto gubernativo de 24 de mayo de 1866". La Gaceta 41 del martes 18 de septiembre de $1877,341$.

Ministerio de Policía. "Decreto, disponiendo que toda fiesta pública solo dure tres días". La Gaceta 52 del sábado 18 de octubre de 1879, 411.

Molina Jiménez, Iván. El que quiera divertirse. Libros y sociedad en Costa Rica (1750-1914). San José: EUCR, 1995.

Molina Jiménez, Iván y Steven Palmer (eds.). Héroes al gusto y libros de moda. Sociedad y cambio cultural en Costa Rica (1750-1900). San José: Editorial Porvenir, 1992.

. El paso del cometa. Estado, política social y culturas populares en Costa Rica (1800-1950). San José: Editorial Porvenir, 1994.

Molina Jiménez, Iván y Patricia Fumero Vargas. La sonora libertad del viento. Sociedad y cultura en Costa Rica y Nicaragua (1821-1914). México D.F.: IPGH, 1997.

Poder Legislativo. "Decreto del 26 de abril”. La Gaceta 105 del miércoles 8 de mayo de 1918, 841.

Rodríguez Rosales, Isolda. Historia de la educación en Nicaragua: Restauración Conservadora (19101930). Managua: HISPAMER, 2005.

Urbina Gaitán, Chester. “Promoción o prevención? Alcoholismo, Estado e Iglesia en Costa Rica (1850-1936)". Repertorio Americano, 7 (1999): 34-46.

"Homogeneizando culturas. Peleas de gallos, corridas de toros y Estado en Costa Rica (1883-1914)". Revista de Ciencias Sociales, (2000): 59-67.

. Costa Rica y el Deporte 1873-1921. Un estudio acerca del origen del fútbol y la construcción de un deporte nacional. Costa Rica: EUNA, 2001.

. "Circo, nigromancia y prestidigitación en Costa Rica (1867-1914). Una aproximación desde la historia social". Revista de Ciencias Sociales, (2002): 97-115.

. "Exclusión social, desarticulación cultural y teatro en El Salvador 1875-1944". Anuario de Estudios Centroamericanos, 29 (2003): 101-111.

. “Cine, Beneficencia y Censura en Guatemala (1896-1920)". Revista de la Universidad de San Carlos de Guatemala, (2006a): 28-34. 
. “Teatro, Estado y Promoción Cultural en Guatemala (1875-1921)”. Anuario de Estudios Centroamericanos, 32, (2006b): 81-95.

. "Estado, sociabilidad y control social en Costa Rica (1950-1971)". Revista de Ciencias Sociales, (2006c): 189-197.

. Origen del Deporte en El Salvador (1885-1943). Realidad y reflexión, 17 (2006d): 1-106.

. Deporte y Nación (1881-1950). El caso del fútbol en Guatemala. Ciudad de Guatemala: FLACSO, 2007a.

. “Estado, Política y Deporte en El Salvador (1885-1921)". Anuario de Investigaciones, 4, (2007b): 79-92.

Chester Urbina. Nicaragüense. Licenciatura en Historia UCR. Maestría en Ciencias Sociales FLACSO Guatemala. Coordinador de la Licenciatura en Historia Universidad Tecnológica de El Salvador 2003-2004. Coeditor de los dos tomos de Historia de El Salvador. Profesor en la Universidad de Costa Rica, Universidad Nacional de Costa Rica, Universidad Centroamericana de El Salvador y Universidad Politécnica de Nicaragua. Tiene más de 100 artículos sobre la historia cultural y del deporte en Centroamérica.

Contacto: chesterurbina@yahoo.com 